\title{
RELAÇÕES ÉTNICO-RACIAIS E LEI N. 10.639/2003: ENTRE TEXTOS E DISCURSOS DE DOCUMENTOS OFICIAIS SOBRE LEGISLAÇÃO EDUCACIONAL DO ESTADO DO PARÁ E DA AMAZÔNIA BRAGANTINA (2003-2017)
}

Taylon Silva Chaves ${ }^{1}$

Raquel Amorim dos Santos ${ }^{2}$

Resumo: Este estudo objetiva examinar o Plano Estadual e Municipal de Educação e Leis do Conselho Estadual e Municipal de Educação do município de Bragança, Pará. A pesquisa é qualitativa, documental e bibliográfica. A análise dos dados considerou a análise do discurso com base no dialogismo discursivo de Bakhtin (2010). Os resultados revelam que os documentos analisados defendem o respeito à diversidade cultural como forma de diminuir as desigualdades sociais, o desenvolvimento de políticas de ações afirmativas como instrumentos de integração da população negra e a criação de proposta curricular multicultural que atenda as demandas dos diferentes grupos étnico-raciais. Concluímos que a efetivação da Lei n. $^{\circ}$ 10.639/2003 é uma possibilidade para o Brasil reverter o quadro histórico de desigualdades raciais e garantir a cidadania da população negra, valorização da diversidade cultural e das identidades negras.

Palavras-chave: Lei n. ${ }^{\circ}$ 10.639/2003; Legislação Educacional; Relações Étnico-Raciais.

\section{ETHNIC-RACIAL RELATIONS AND LAW NO. 10.639 / 2003: BETWEEN TEXTS AND SPEECHES OF OFFICIAL DOCUMENTS ON EDUCATIONAL LEGISLATION OF THE STATE OF PARÁ AND AMAZON BRAGANTINA (2003-2017)}

\begin{abstract}
This study aims to examine the State and Municipal Plan of Education and Laws of the State and Municipal Council of Education of the municipality of Bragança, Pará. The research is qualitative, documental and bibliographical. Data analysis considered discourse analysis based on Bakhtin's discursive dialogism (2010). The results show that the documents analyzed defend respect for cultural diversity as a way to reduce social inequalities, the development of affirmative action policies as instruments for the integration of the black population, and the creation of a multicultural curriculum proposal that meets the demands of different ethnic groups rights. We conclude that the implementation of Law 10.639 / 2003 is a possibility for Brazil to reverse the historical framework of racial inequalities and guarantee the citizenship of the black population, valuing cultural diversity and black identities.
\end{abstract}

Keywords: Law no.10.639/2003; Educational Legislation; Ethnic-Racial Relations.

\section{RELATIONS INTERETHNIQUES ET LOI N ${ }^{\circ} 10.639$ / 2003: ENTRE TEXTES ET DISCOURS DE DOCUMENTS OFFICIELS RELATIFS A LA LEGISLATION EN}

\footnotetext{
1 Graduando em Licenciatura Plena em Pedagogia pela UFPA. Professor/mediador na rede privada Centro Educacional João Paulo II, em Bragança/PA e bolsista de iniciação científica na UFPA, Campus de Bragança, por meio do Núcleo de Estudos e Pesquisas em Educação, Currículo, Formação de Professores e Relações Étnico-Raciais, NEAFRO/UFPA. E-mail: taylon.silva1998@gmail.com

${ }^{2}$ Professora Adjunta A da Universidade Federal do Pará, Campus Universitário de Bragança, Faculdade de Educação. Professora do Programa de Pós-Graduação em Linguagens e Saberes na Amazônia (PPLSA), Linha de Pesquisa: Educação, Cultura e Sociedade. Pesquisadora do Núcleo de Estudos e Pesquisa sobre Formação de Professores e Relações Étnico-Raciais (GERA/UFPA). E-mail: rakelamorim@yahoo.com.br
} 


\section{O}

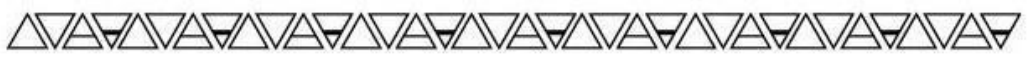

MATIERE D'EDUCATION DANS LES ÉTATS DE PARA ET AMAZON BRAGANTINA (2003-2017)

Résumé: Cette étude a pour objectif d'examiner le plan national et municipal d'éducation et les lois du Conseil national de l'éducation et municipal de la municipalité de Bragança (Pará), à la fois qualitatif, documentaire et bibliographique. L'analyse des données a pris en compte l'analyse du discours basée sur le dialogisme discursif de Bakhtin (2010). Les résultats montrent que les documents analysés défendent le respect de la diversité culturelle en tant que moyen de réduire les inégalités sociales, l'élaboration de politiques d'action positive en tant qu'instruments d'intégration des populations noires et la création d'une proposition de programme multiculturel qui réponde aux exigences des différents groupes ethniques. droits. Nous concluons que la mise en œuvre de la loi 10.639 / 2003 est une possibilité pour le Brésil de renverser le cadre historique des inégalités raciales et de garantir la citoyenneté de la population noire, en valorisant la diversité culturelle et les identités noires.

Mots-clés: Loi $\mathrm{n}{ }^{\circ}$ 10.639/2003; Législation educative; Relations ethniques-raciales.

\section{RELACIONES ÉTNICO-RACIALES Y LEY No 10.639 / 2003: ENTRE TEXTOS Y DISCURSOS DE DOCUMENTOS OFICIALES SOBRE LEGISLACIÓN EDUCATIVA DEL ESTADO DE PARÁ Y DE LA AMAZONIA BRAGANTINA (2003-2017)}

Resumen: Este estudio objetiva examinar el Plan Estadual y Municipal de Educación y Leyes del Consejo Estadual y Municipal de Educación del municipio de Bragança, Pará. La investigación es cualitativa, documental y bibliográfica. El análisis de los datos consideró el análisis del discurso con base en el dialogismo discursivo de Bakhtin (2010). Los resultados revelan que los documentos analizados defienden el respeto a la diversidad cultural como forma de disminuir las desigualdades sociales, el desarrollo de políticas de acciones afirmativas como instrumentos de integración de la población negra y la creación de una propuesta curricular multicultural que atienda las demandas de los diferentes grupos étnico -raciais. Concluimos que la efectividad de la Ley $\mathrm{n}^{\circ} 10.639$ / 2003 es una posibilidad para que Brasil revertir el cuadro histórico de desigualdades raciales y garantizar la ciudadanía de la población negra, valorización de la diversidad cultural y de las identidades negras.

Palabras clave: Ley no 10.639/2003; Legislación Educativa; Relaciones Étnico-Raciales.

\section{INTRODUÇÃO}

O estudo analisa a implementação da Lei n. ${ }^{\circ}$ 10.639/2003 em escolas públicas de Educação Básica situadas em comunidades do entorno de manguezais da Reserva Extrativista Marinha Caeté-Taperaçu (Resex-Mar), em Bragança, município do nordeste do estado do Pará. A pesquisa é qualitativa, pois possibilita compreender os múltiplos e diferentes significados que emergem dos diferentes contextos sociais, possíveis de serem percebidos em relações e partilhas densas de conhecimento (Chizzotti, 2010).

Incialmente realizou-se a análise documental do Plano Estadual e Municipal de Educação e das Leis do Conselho Estadual e Municipal de Educação. A pesquisa documental constitui-se como procedimento relevante para ampliar a compressão contextual, histórica e sociocultural de documentos escritos por possibilitar a emersão 
dos principais discursos de determinados grupos sociais e políticos (Sá-Silva et al, 2009).

Além disso, a pesquisa bibliográfica possibilitou a realização de aproximações sucessivas entre o objeto de estudo e as diversas fontes bibliográficas do campo das relações étnico-raciais. Esse procedimento “[...] requer do realizador atenção constante aos 'objetivos propostos' e aos pressupostos que envolvem o estudo para que a vigilância epistemológica aconteça [...]” (Lima; Mioto, 2007, p. 40).

A análise dos dados considerou a análise do discurso com base no dialogismo discursivo de Mikhail Bakhtin (2010). Nessa perspectiva, o dialogismo permite compreender a existência de diversos discursos que emergem dos documentos educacionais oficiais, que podem ser percebidos, destacados e interpretados pelo pesquisador.

Além disso, autores como Hasenbalg (2005), Munanga (2004), Schwarcz (1993), Carone e Bento (2014), Ortiz (2006), Gomes (2012b), Coelho (2006), Santos (2009), André (2008), entre outros, foram fundamentais para sustentar as análises, pois em suas distintas abordagens contribuíram para compreendermos a Lei n. ${ }^{\circ}$ 10.639/2003 a partir de um contexto de lutas e resistências da população negra de nosso país.

Os documentos analisados revelam que a temática étnico-racial e a Lei n. ${ }^{\circ}$ 10.639/2003 são questões invisíveis nos discursos oficiais do campo educacional do estado do Pará e do município de Bragança. Raramente observa-se a prescrição de ações relacionadas ao enfrentamento do racismo, preconceito e discriminação raciais.

Contudo, verifica-se que esses documentos defendem o respeito à diversidade cultural como forma de diminuir as desigualdades sociais, o desenvolvimento de políticas de ações afirmativas como instrumentos de integração social da população negra e a criação de proposta curricular multicultural, que inclua as diferentes expressões culturais.

Destarte, essa legislação emerge no cenário educacional brasileiro a partir das reinvindicações dos movimentos negros (Rocha, 2014; Santos et al, 2013). A Lei n. ${ }^{\text {o }}$ 10.639/03 é uma vitória para o povo negro brasileiro, pois garante que a história e cultura dos africanos e afro-brasileiros tornem-se conteúdos obrigatórios no currículo, o que também viabilizará a valorização das identidades negras.

A luta política dos movimentos negros reflete a ausência do negro no contexto educacional, como consequência de sua histórica exclusão social (Coelho, 2006; Coelho 
et al, 2016; Rocha, 2014; Santos et al, 2013, 2014a) e urgência da implementação de políticas públicas que garantam a integração de grupos historicamente estigmatizados.

Essas políticas compõem a legislação antirracista brasileira, formam um conjunto de dispositivos legais considerados como indutores de uma política educacional voltada para a afirmação da diversidade cultural e da concretização de uma educação para as relações étnico-raciais nas instituições de ensino.

A legislação funciona como mecanismo reparador das distorções históricas que as narrativas hegemônicas fizeram prosperar na educação do país e, consequentemente, no imaginário social (Santos et al, 2013). A Lei n. ${ }^{\circ} 10.639 / 2003$ é um desses dispositivos e possibilita a desconstrução de estereótipos e a construção positiva das identidades negras (Silvério; Trinidad, 2012; Gomes, 2007, 2012b).

Por sua vez, a implementação dessa Lei exige ações para além da Educação Básica e do Ensino Superior; isso significa que organizações, órgãos de ensino, Ministério Público, Conselhos de Educação, movimentos sociais, entre outros agentes, também tem grande parcela nesse processo, pois poderão mover ações e práticas para que se efetive na Educação Básica e no Ensino Superior (Santos, 2009, 2014b).

A Lei completa quinze anos, no entanto, continua invisível na escola, Instituições de Ensino Superior, cursos de formação de professores e, consequentemente, no currículo voltado para a diversidade cultural, racial e social brasileira, sendo necessária, para reverter este quadro, uma política intersetorial que reúna esforços de diferentes agentes sociais para efetiva-la (Santos, 2009; Coelho; Coelho, 2008; Santos et al, 2015).

Por meio dessa política, a Lei possibilitará mudança diante da história, de forma a desmistificar os conteúdos acerca da África, da diáspora africana, dos afro-brasileiros, e incluir uma dimensão social e cultural necessária à formação de crianças, adolescentes, jovens e adultos da sociedade brasileira (Santos, 2009, 2014b; Santos et al, 2013, 2014a, 2015), sendo, portanto, um marco para a educação das relações étnicoraciais e para a valorização da diversidade cultural.

Na primeira seção analisaremos o Plano Estadual de Educação do Pará e o Plano Municipal de Educação de Bragança. No segundo momento, refletiremos acerca da Resolução n. ${ }^{\circ}$ 01, de 05 de janeiro de 2010, do Conselho Estadual de Educação do Pará, e a Resolução n. ${ }^{\circ}$ 01, de 11 de janeiro de 2017, do Conselho Municipal de Educação de Bragança. Por fim, apresentamos algumas considerações sobre a implementação da Lei 
n. ${ }^{\circ}$ 10.639/2003 na Educação Básica da Amazônia Bragantina a partir desses documentos.

\section{RELAÇÕES ÉTNICO-RACIAIS E LEI N. 10.639/2003: ENTRE TEXTOS E DISCURSOS DO PLANO ESTADUAL DE EDUCAÇÃO DO PARÁ E PLANO MUNICIPAL DE EDUCAÇÃO DE BRAGANÇA}

As questões étnico-raciais estão presentes em documentos oficiais que compõem a legislação educacional brasileira? O que o Plano Estadual de Educação do Pará e o Plano Municipal de Bragança dizem sobre os africanos e afro-brasileiros? Quais suas contribuições para a implementação da Lei n. ${ }^{\circ}$ 10.639/2003 no currículo oficial?

Segundo Gomes (2012a) a implementação da Lei depende não apenas de ações e políticas intersetoriais, articulação com a comunidade e com os movimentos sociais, mudança nos currículos das Licenciaturas e da Pedagogia, mas também de regulamentação e normatização no âmbito estadual e municipal, de formação inicial, continuada e em serviço dos profissionais da educação e gestores dos sistemas de ensino e das escolas.

Diante disso, questionamos: Quais as principais implementações da Lei $\mathrm{n}^{\mathbf{o}}$ 10.639/2003 na Educação Básica das escolas situadas no entorno de manguezais da Reserva Extrativista Marinha Caeté-Taperaçu (Resex-Mar), em Bragança, Pará? Quais os discursos dos documentos oficiais que versam sobre a temática étnico-racial? Quais as ações previstas para a implementação da Lei?

Historicamente a temática étnico-racial está ausente no currículo da Educação Básica e do Ensino Superior (Coelho, 2006; Santos, 2009, 2014b; Santos et al, 2013), contudo, a Lei n. ${ }^{\circ}$ 10.639/2003 exerceu forte influência na política curricular, desencadeando reformulações no âmbito das escolas públicas e privadas, Instituições de Ensino Superior e cursos de formação de professores.

Os Planos de Educação analisados denotam essa influência, pois, embora apresentem discussões teóricas e legais não sistemáticas e circunstanciais sobre a temática, esboçam incursões acerca de questões correlatas, como o respeito às diferenças e a defesa de políticas de ações afirmativas para a integração da população negra no contexto educacional.

O Plano Estadual de Educação do Pará foi aprovado pela Lei Estadual n. ${ }^{\circ}$ 8.186, em 23 de junho de 2015, composto por vinte metas para a educação do estado do Pará e 
uma série de estratégias para a superação das principais problemáticas diagnosticados pelo Governo do Estado na Educação Básica.

De acordo com esse documento existe uma enorme contradição no estado: enquanto dispõe de recursos naturais abundantes muitas pessoas ainda vivem em condições de extrema pobreza e, assim como os demais estados brasileiros, é marcado por desigualdades sociais. Segundo o Plano Estadual, essas desigualdades se referem especialmente à "[...] condições de infraestrutura mínima para promover a qualidade de vida, as quais constituem-se em entraves ao desenvolvimento social da população paraense [...]" (Pará, 2015, p. 11).

Além disso, assevera que o Pará “[...] herda as consequências do projeto colonizador na região amazônica, iniciado por meio da ocupação do espaço, primeiramente ao longo do rio Amazonas e seus afluentes e do rio Tocantins [...]" (Pará, 2015, p. 12), o que ocasionou desigualdades sociais entre grupos étnico-raciais, situação marcante na sociedade brasileira desde a abolição da escravatura (Hasenbalg, 2005; Munanga, 2004).

Segundo Hasenbalg (2005) o Brasil é marcado pela desigualdade racial como consequência da ausência de projeto social para a inclusão do negro após a abolição da escravidão. O negro sempre esteve à mercê de um cenário capitalista competitivo e excludente, sem dispor de condições materiais e sociais semelhantes àquelas que dispõem a população branca de classe média. Para ele, após a "libertação" as oportunidades de trabalho e ascensão para brancos e "não brancos" continuaram desiguais.

Diante desse cenário, o Plano Estadual deseja "[...] assegurar o direito social a educação para a diversidade étnica-cultural que abriga o território paraense [...]" (Pará, 2015, p. 12) a fim de superá-lo e garantir qualidade de vida à população, tanto nos aspectos materiais quanto sociais, no sentido de condições objetivas e desconstrução de visões estereotipadas em relação aos negros para sua integração e para a efetivação de sua cidadania. Desse modo, o documento expressa o dever do Poder Público em atender às demandas sociais da região paraense e amazônica.

Como solução para a superação desse cenário, o documento preceitua que “[...] políticas públicas efetivas devem ser implementadas para que o Estado do Pará supere as históricas desigualdades educacionais [...]" (Pará, 2015, p. 76), assertiva que comunga com o pensamento de alguns autores que defendem a criação de políticas 
públicas, especialmente de ações afirmativas para o enfrentamento da desigualdade e para a visibilização positiva de grupos historicamente estigmatizados (Coelho et al, 2016; Munanga, 2006).

Diante disso, percebemos que a implementação da Lei n. ${ }^{\circ}$ 10.639/2003 não pode ser responsabilidade apenas de instituições de ensino. A complexidade das relações assimétricas entre brancos e negros em que opera o racismo e o preconceito racial, afetando diretamente a população negra, exige ações intersetoriais e efetivas de vários agentes sociais, sendo que o Poder Público recebe grande papel por ser o difusor das políticas públicas (Munanga, 2004) e desencadeador de ações em nível macro (Santos, 2014b).

Com efeito, Munanga (2006) defende a criação de políticas de ações afirmativas como mecanismos reparadores das distorções históricas experimentadas pela população negra em todos os espaços sociais. Dessa forma, políticas específicas devem ser implementadas para garantir a superação destas distorções e, neste caso, das disparidades entre brancos e negros no contexto educacional.

O Plano Estadual abaliza a relevância das políticas de ações afirmativas, especialmente da Lei n. ${ }^{\circ}$ 10.639/2003 que pode garantir equidade entre os diferentes grupos étnico-raciais e enfrentar a discriminação racial, operante na sociedade brasileira (Guimarães, 2008; Munanga, 2004). Além disso, estabelece a criação do currículo multicultural, instrumento capaz de valorizar a história e cultura africana e afrobrasileira.

O discurso desse documento é contundente, pois desconstrói a ideia de que a escola é a única encarregada de garantir a valorização das diferenças, atribuindo grande participação ao Poder Público nesse processo (Santos, 2009, 2014b). Este, através de leis e ações sistemáticas exerce papel contumaz na luta contra a discriminação racial, sendo um dos agentes de maior responsabilidade na efetivação dos direitos da população negra. Por fim, a partir desse discurso reafirmamos que a Lei n. ${ }^{\circ}$ 10.639/2003 influenciou significativamente a política curricular brasileira, configurando-se como mecanismo reparador de uma história marcada pela invisibilização e marginalização do negro.

Essa Lei contribui para inserir a questão étnico-racial, os direitos humanos e a diversidade cultural no cerne da política curricular no Brasil, sendo um dos mecanismos para contestar a ausência da história e cultura africana e afro-brasileira no currículo da 
Educação Básica e do Ensino Superior, Projeto Político-Pedagógico, Planos de Ensino e as desigualdades raciais introduzidas no imaginário da Educação Básica e das Instituições de Ensino Superior (Santos et al, 2013, 2014a, 2015). Em suma, é um dispositivo legal que influenciou a elaboração do Plano Estadual e tantos outros documentos educacionais brasileiros para a realização de uma educação para as relações étnico-raciais.

Diante disso, tornou-se interessante investigar a existência ou não de textos e discursos sobre a Lei n. ${ }^{\circ}$ 10.639/2003 e relações étnico-raciais no principal documento educacional que rege a Educação Básica na Amazônia Bragantina. Tal documento é o Plano Municipal de Educação, criado por meio da Lei Municipal n. ${ }^{\circ}$ 4.391, em 22 de Junho de 2015, estruturado com 20 metas para a Educação Básica e Ensino Superior e as respectivas estratégias para alcança-las, assemelhando-se àquelas previstas no outro Plano Estadual sem, contudo, deixar de imprimir sua identidade ao documento.

Inicialmente, reportamo-nos aos discursos desse documento sobre as políticas de ações afirmativas, pois estabelece que a Educação Básica deve "[...] promover ações afirmativas através do Projeto Político-Pedagógico (PPP) da escola e da proposta Curricular [...]" (Bragança, 2015, p. 95) para o atendimento das demandas dos diversos grupos sociais, enfatizando a participação da escola no processo de valorização da história e cultura africana e afro-brasileira e de outros sujeitos historicamente estigmatizados e excluídos no currículo oficial. A partir dessa assertiva identifica-se um ponto de conexão entre o Plano Estadual e Municipal, pois ambos revelam a eficácia das ações afirmativas, da mudança de posturas pedagógicas e de um currículo que atenda à temática étnico-racial.

Nesse sentido, o campo curricular inclui a questão étnico-racial e possibilita a visibilização positiva dos sujeitos negros, devendo ser entendido como um conjunto de "[...] conhecimentos e práticas produzidas em contextos concretos e em dinâmicas sociais, políticas e culturais, intelectuais e pedagógicas [...]" (Candau; Moreira, 2007, p. 9). Dessa forma, configura-se enquanto documento marcado pela pluralidade de vozes e discursos, sendo necessário possibilitar que essa diversidade seja reconhecida e valorizada.

Nessa perspectiva destaca-se a concepção de currículo multicultural, que emerge da inclusão do tema diversidade na Lei de Diretrizes e Bases da Educação Nacional (LDB n. ${ }^{\circ}$ 9.394/96), desencadeada principalmente pela atuação dos movimentos sociais 
em prol de uma educação democrática, transformadora, emancipatória, cidadã e inclusiva (Oliveira, 1997), que prima por uma pratica pedagógica integradora da pluralidade cultural (Candau; Moreira, 2007, 2008). A LDB/96, por exemplo, em seu artigo 26 estabelece a diversidade cultural como conteúdo obrigatório no currículo oficial, atribuindo aos sistemas e estabelecimentos de ensino a responsabilidade de inclui-la no currículo a fim de tornar a escola um espaço de inclusão e valorização cultural.

A escola deve "[...] revisar os currículos de forma participativa que atenda às necessidades de um currículo multicultural [...]" (Pará, 2015, p. 77), promover ações voltadas ao atendimento de demandas sociais por meio da proposta curricular (Bragança, 2015, p. 95), incluir a temática diversidade por meio dos conteúdos disciplinares ou no que tange à parte diversificada do currículo e desenvolver práticas pedagógicas que visibilizem e valorizem a história e cultura dos diferentes grupos étnico-raciais (Santos, 2009, 2014b). Dessa forma, identificamos nos Planos Estadual e Municipal a obrigatoriedade de uma política curricular que reconheça e valorize a diversidade cultural.

Segundo o Plano Estadual os conteúdos disciplinares deverão ser trabalhados “[...] de maneira flexível e diversificada [...], em dimensões como ciência, trabalho, linguagens, tecnologia, cultura e esporte [...]" (Pará, 2015, p. 39). Para o Plano Municipal poderão desdobrar-se "[...] por meio da arte-cultura e esporte-lazer [...], da realidade social, cultural, ambiental e política [...]” (Bragança, 2015, p. 78). Desse modo, os documentos rompem com o ensino eurocêntrico, excludente e pautado em representações estereotipadas e racistas em relação aos negros (Munanga, 2004).

Nesse contexto, verificamos que os Planos de Educação evidenciam indiscutivelmente aspectos pedagógicos e culturais do currículo multicultural (Candau; Moreira, 2007, 2008). Para garantir um trabalho educativo capaz de valorizar as diferenças torna-se imprescindível repensarmos a proposta curricular e investir em novas possibilidades de mudança por meio do ensino e das relações sociais, enfrentando preconceitos e discriminações e estabelecendo relações positivas na escola (Santos, 2009).

Ao observarmos os corredores e salas de aula da escola identificamos diferenças, pois cada sujeito que a compõe expressa um costume, corte de cabelo, modo de falar, comportamento, identidade, etc. de maneira muito particular. Tal situação evoca a 
urgência de trabalharmos a diversidade cultural e, mais especificamente, a temática étnico-racial para atender às demandas de diferentes grupos que buscam reconhecimento e às exigências legais que estabelecem a construção de uma educação democrática e cidadã.

Em relação à diversidade, a LDB/96 em seu Art. 3º, Inciso XII, estabelece a "[...] consideração com a diversidade étnico-racial [...]" (Brasil, 1996), como um dos princípios da educação nacional, tornando explícita a responsabilidade do Estado brasileiro em incluir no campo das políticas públicas as demandas dos movimentos sociais (Oliveira, 1997), especificamente dos movimentos negros (Rocha, 2014). Dessa forma, a diversidade passa a ser considerada não somente de maneira geral, como diversidade cultural, mas pensada no sentido plural, enquanto diversidades (Canen; Moreira, 2007, 2008).

Essa inclusão das diversidades denota o compromisso que a sociedade brasileira tem em enfrentar o racismo e garantir justiça social, responsabilidade assumida a partir da ação política dos movimentos sociais negros (Rocha, 2014). A atuação desses movimentos permitiu inserir na agenda política do Estado algumas questões dos afrobrasileiros e, consequentemente, mecanismos para sua integração e valorização (Santos, 2014a). Dessa forma, o Poder Público e as instituições de ensino deverão promover ações afirmativas direcionadas à população negra e uma educação para as relações étnico-raciais que contribuam para a desconstrução de estigmatizações e preconceitos.

O Plano Estadual de Educação do Pará, por exemplo, explicita perfeitamente essa influência dos movimentos sociais ao estabelecer a construção de uma relação entre diversidade e Educação Básica (Pará, 2015), a fim de incluir aspectos da história e cultura de grupos historicamente estigmatizados, como é o caso da população negra que experimenta a exclusão social e a desvalorização cultural (Munanga, 2004) em virtude desta relação não ter sido estabelecida tempestivamente nas escolas e nas Instituições de Ensino Superior, especialmente nos cursos de formação de professores (Coelho, 2006).

Os Planos de Educação analisados concebem a diversidade cultural considerando vários desdobramentos, como a diversidade étnica-racial, de gênero, de estética, de identidade etc. (Gomes, 2003, 2012b), defendendo a criação de proposta curricular multicultural que corresponda a esta complexidade das sociedades dinâmicas (Hall, 2001). Desse modo, os documentos traduzem as exigências da legislação 
antirracista brasileira e acompanham os movimentos transformadores em prol de uma educação para a diversidade cultural e étnico-racial (Coelho et al, 2016).

Contudo, embora o Plano Estadual estabeleça a criação de um currículo multicultural, limita-se, pois não incorre sobre seus fundamentos e aplicabilidade na Educação Básica, constituindo-se como um discurso frágil acerca desta perspectiva curricular. Mas, no que tange à temática desta Pesquisa, elenca que a diversidade étnicoracial deve ser trabalhada na escola para que se eleve a qualidade da Educação (Pará, 2015), avançando no sentido de considerar a questão étnico-racial enquanto fundamental e não como secundária, como o fazem muitas escolas brasileiras (Santos et $a l, 2013)$.

O Plano Municipal de Educação de Bragança, por sua vez, traduz a discussão sobre diversidade a partir do compromisso da sociedade e do Estado com a reparação das disparidades entre brancos e negros. Segundo o documento, a Educação Básica deve:

Promover atendimento à educação humanizadora e que contribua para a construção de uma sociedade mais justa e solidária, que respeite a diversidade e as diferenças e minimize a segmentação social, possibilitando a inserção de todos no processo produtivo e na produção de sua própria subsistência (Bragança, 2015, p. 96).

O respeito às diferenças é uma atitude indispensável para o processo de valorização do outro, de sua identidade e modos de ver o mundo (Santos, 2009). Respeitar a diversidade possibilita reformular as representações em relação aos negros, repensar a forma como são tratados e imprimir uma visão humanizadora à educação. Tal atitude é fundamental para que os sujeitos negros sejam considerados em suas especificidades, visibilizados positivamente e incluídos dignamente aos espaços sociais (Munanga, 2004; Gomes, 2012a).

Entretanto, é necessário refletirmos sobre a invisibilidade da diversidade cultural (Coelho et al, 2016) e, mais especificamente, do sujeito negro nas instituições de ensino (Coelho, 2006), pois a construção da identidade nacional brasileira, baseada na herança branca europeia (Munanga, 2004) não permitiu a inclusão dos africanos e afrobrasileiros no rol de povos que foram significativos para a construção do Brasil, ao contrário, incitou a discriminação racial e a exclusão social (Ortiz, 2006).

Santos e Silva (2017) afirmam que a construção dessa identidade estava sob a égide de teorias científicas racistas que procuravam justificar a suposta inferioridade da 
população negra. Para Ortiz (2006), a identidade nacional idealizada não visibilizou o negro, pois o ideal para os nacionalistas da época era o país assemelhar-se aos países desenvolvidos da Europa. Nesse processo, precisava ser preponderantemente branco, desconsiderando qualquer possibilidade do afro-brasileiro alcançar reconhecimento como cidadão, em virtude também de ser considerado inferior e degenerado (Schwarcz, 1993).

Nesse contexto, a diversidade cultural não era reconhecida e não se cogitava a ideia do país ser concebido como um lugar de múltiplas identidades o que, consequentemente, tornava a questão racial invisível no currículo oficial (Gomes, 2003; Coelho, 2006). Buscava-se, ao contrário, sustentar uma identidade única e excludente (Ortiz, 2006). Somente em período recente é que a sociedade brasileira passa a lidar com a pluralidade de outra forma, ainda que envolvida por preconceitos e estigmatizações, mas agora inclinada a considerar sua existência (Munanga, 2004).

A legislação educacional brasileira, especialmente a partir da Lei n. ${ }^{\circ}$ 10.639/2003 evidencia essa nova postura, à medida que procura desconstruir visões estereotipadas em relação aos negros enraizadas no imaginário social da sociedade brasileira (Santos et al, 2013). Os Planos de Educação analisados, por exemplo, esboçam a existência da pluralidade no contexto brasileiro em um movimento de reformulação curricular a fim de tratar de forma positiva grupos étnico-raciais historicamente estigmatizados, contribuindo para a valorização das diversas expressões culturais (Gomes, 2003).

Com a pretensão de atender às normativas legais para a educação escolar, o Plano Estadual de Educação do Pará assegura que "[...] a escola deve se constituir, ao mesmo tempo, em um espaço da diversidade e da pluralidade [...], baseado no princípio educativo e emancipador [...]" (Pará, 2015, p. 110). Da mesma forma, o Plano Municipal de Educação de Bragança estabelece que a Educação Básica deve considerar as "[...] especificidades e diversidades socioculturais, com vistas a garantir, além do acesso, a permanência, o sucesso do aluno e a qualidade da educação escolar [...]" (Bragança, 2015, p. 34).

Os discursos desses documentos traduzem a influência da Lei n. ${ }^{\circ}$ 10.639/2003 na elaboração da política curricular, pois além de introduzir a temática étnico-racial, integrou a dimensão da diversidade cultural na prática educativa. Isso significa que essa Lei é capaz de integrar outros grupos étnico-raciais para além de uma valorização 
restrita ao segmento negro. Para Santos et al (2016), a Lei inclui questões para além do ensino de história e cultura africana e afro-brasileira, carregando sentidos para a realização de uma educação humanizadora e compromissada com a valorização das diferenças.

Nessa perspectiva humanizadora da Educação, considerando as especificidades dos estudantes da Amazônia Bragantina, os Planos de Educação analisados afirmam que a escola é marcada pela existência de diversas identidades, situação que enriquece o contexto escolar (Santos, 2009). Os documentos também salientam que a prática educativa deve contribuir para a valorização dessas identidades, a fim de que os sujeitos sejam visibilizados positivamente (Gomes, 2003; André, 2008).

O Plano Estadual, por exemplo, estabelece ser necessário a “[ [...] preservação da identidade cultural [...]" (Pará, 2015, p. 72), especialmente das comunidades indígenas e quilombolas, historicamente estigmatizadas (Munanga, 2004). O Plano Municipal, por sua vez, considera que a identidade cultural da Amazônia Bragantina é "muito forte" (Bragança, 2015, p. 19), marcante e peculiar e que, portanto, deve ser respeitada e valorizada.

Os dois discursos são contundentes porque denotam a importância da valorização da diversidade e, intrinsecamente, das diferentes identidades. Cabe destacar que a instituição escolar tem papel importante nesse processo, pois a construção da identidade sofre influências de fatores externos, sociais e culturais (André, 2008). Desse modo, a escola pode contribuir para a construção e representação positiva da identidade dos afro-brasileiros e de outros que experimentam a exclusão social por assumir identidades diferentes dos padrões hegemônicos (Candau; Moreira, 2008; Gomes, 2012a).

Destarte, a escola é um espaço onde são "[...] partilhadas, representadas e construídas relações [...]" que podem tanto reproduzir desigualdades como podem estimular o respeito às diferenças (Santos, 2009, p. 18). Isso significa que ela pode funcionar como um ambiente subversivo à homogeneização cultural, desencadeando um processo de valorização da diversidade e das identidades dos estudantes, extremamente complexas e diversas (Canen; Moreira, 2007; Gomes, 2003; André, 2008).

Nesse sentido, reportamo-nos ao papel social da Educação, que deve ser compromissada com a transformação social com vista à prática da cidadania, solidariedade, igualdade e justiça social (Brandão, 1981; Freire, 2000). Com efeito, 
Brandão (1981) abaliza que a Educação tem um papel transformador capaz de provocar modificações no sujeito e no contexto social, transformar relações, possibilitando uma formação humana que reconheça e valorize as diferenças.

Os Planos de Educação estudados manifestam esse papel, pois se baseiam na perspectiva democrática, estabelecida a partir da LDB n. ${ }^{\circ}$ 9.394/1996. Segundo o Plano Estadual, a Educação é um “[...] elemento indutor de transformação e emancipação sociais [...]" (Pará, 2015, p. 13), sendo, consequentemente, um espaço para a mudança das relações sociais entre grupos étnico-raciais, no sentido de enfrentar o racismo e discriminação racial, buscando simetria e respeito nessas relações (Santos et al, 2013).

Desse modo, os documentos estudados inserem-se na perspectiva democrática do ensino, revelando a emergência de outras vozes em seus textos (Bakhtin, 2010). Apresentam os discursos políticos dos movimentos sociais em prol da cidadania (Oliveira, 1997), sobretudo, os movimentos sociais negros (Rocha, 2014), além dos discursos das Diretrizes Curriculares Nacionais para a Educação das Relações ÉtnicoRaciais e para o Ensino de História e Cultura Africana e Afro-Brasileira (Brasil, 2004).

De acordo com essas Diretrizes, semelhante ao que dispõe o Plano Estadual de Educação do Pará e o Plano Municipal de Bragança, a Educação:

[...] constitui-se um dos principais ativos e mecanismos de transformação de um povo e é papel da escola, de forma democrática e comprometida com a promoção do ser humano na sua integralidade, estimular a formação de valores, hábitos e comportamentos que respeitem as diferenças e as características próprias de grupos e minorias (Brasil, 2004, p. 07).

Desse modo, garantir a transformação social deve ser um dos objetivos da educação (Freire, 2009), por isso, não podemos desenvolver um trabalho educativo restrito a padrões europeus que são excludentes e mantém intactas as relações de poder, ao contrário, devemos elaborar um currículo que contemple a história e cultura de outros grupos étnico-raciais a fim de efetivar mudanças na estrutura das relações sociais (Munanga, 2004; Gomes, 2012b).

Por essa razão, o currículo, carregado de representações estigmatizadas em relação aos africanos e negros brasileiros, deve ser reformulado para que visibilize positivamente esses sujeitos. Os Planos de Educação estudados, influenciados pela legislação educacional voltada para a diversidade cultural, defendem a construção de um currículo multicultural que garanta mudanças, no sentido de minimizar as desigualdades sociais. 
Esses documentos abalizam que o currículo é um instrumento importante para recontarmos a história do africano e do negro brasileiro, na tentativa de superar as narrativas racistas que são reproduzidas no cotidiano escolar. Essas narrativas são excludentes e foram reproduzidas historicamente na sociedade brasileira (Coelho et al, 2016), imbricadas no imaginário social (Santos et al, 2013) e que dificultam a valorização da cultura africana e afro-brasileira (Munanga, 2004).

Historicamente, faculdades, institutos históricos e geográficos e museus se constituíram como vozes de destaque na narrativa da história brasileira, eram instituições do conhecimento das elites brancas que desprezavam a história e cultura dos africanos e afro-brasileiros, reproduziam relações de poder e sustentavam uma hierarquia das raças, situando a negra como a mais inferior (Schwarcz, 1993). Dessa forma, a história oficial foi palco para o protagonismo do europeu, silenciando as vozes dos sujeitos negros (Coelho et al, 2016).

Schwarcz (1993) destaca que a história oficial representou negativamente os negros, considerando-os como seres inferiores, degenerados e depravados, causando sérias consequências no campo curricular, que também renegou a história dos povos africanos (Santos et al, 2013). Essa realidade decorre das relações de poder existentes na construção e consolidação do currículo, pois estão imbricados em sua produção outros processos de dominação centrados na raça e na etnia (Silva, 2009).

Segundo Silva (2009, p. 149), “[...] Todo conhecimento depende da significação e esta, por sua vez, depende de relações de poder [...]". Isso significa que na elaboração do currículo alguns conhecimentos são supervalorizados, pois são estabelecidos a partir da concepção de ensino de grupos hegemônicos, nesse caso, as elites brancas brasileiras, ao passo que outros, especialmente acerca da história e cultura africana e afro-brasileira, são estigmatizados, dispostos como se fossem desnecessários e irrelevantes.

A sociedade brasileira é marcada pela supervalorização do europeu colonizador, especificamente seus costumes, valores, hábitos, história e cultura (Candau; Moreira, 2008). Em consequência, a voz do sujeito negro foi silenciada, pois não havia espaço para compartilhar, sem experimentar preconceitos, o seu modo de perceber a realidade e de expressar sua cultura (Coelho et al, 2016). Por esse motivo: “[...] a escola sempre teve dificuldades em lidar com a pluralidade e a diferença racial. Tende a silenciá-la e 
neutralizá-la. Sente-se mais confortável com a homogeneização e a padronização dos processos escolares" (Moreira; Candau, 2003, p.161 apud Santos, 2009, p. 54).

Nesse contexto, a escola funcionou como reprodutora de preconceitos e acabou desenvolvendo um currículo eurocêntrico. Foi somente a partir da Lei n. ${ }^{\circ}$ 10.639/2003 que essa realidade excludente passa a ser enfrentada de forma incisiva. A Lei tem por finalidade visibilizar o sujeito negro, abandonando a prática de contar sua história apenas pelo prisma do processo de escravização no Brasil colonial, evidenciando sua contribuição para a formação do país, a riqueza de sua cultura, bem como superar estereótipos, como aquele em que é representado apenas como escravo (Silvério; Trinidad, 2012).

Para que se constitua uma nova forma de contar a história do africano e do negro brasileiro, a fim de desconstruir esse ensino eurocêntrico, torna-se necessário a elaboração de um currículo multicultural, conforme estabelece o Plano Estadual de Educação do Pará. O currículo multicultural é uma forma diferenciada de recontar a história do negro, desenvolvido a partir da inclusão da diversidade cultural no currículo oficial, objetiva a integração sistemática e crítica das inúmeras e complexas culturas onde é produzido conhecimento a fim de visibilizá-las positivamente (Candau; Moreira, 2007, 2008).

Com efeito, o Plano Municipal de Educação de Bragança estabelece ser necessário direcionar as "[...] ações educativas para atender as necessidades dos educandos (as) [...], descendentes de indígenas e afro-brasileiros [...]” (Pará, 2015, p. 58), com o propósito de considerar suas especificidades, integrando ao currículo oficial outras culturas para além de uma visão eurocêntrica de ensino (Candau; Moreira, 2007, 2008).

Especificamente, o Plano Estadual de Educação do Pará estabelece a criação do currículo multicultural como forma de enfrentamento à discriminação racial, mesmo que a questão seja abordada tacitamente. Por outro lado, o Plano Municipal de Educação de Bragança comunga melhor com o pensamento de Gomes (2012b) acerca do currículo descolonizado.

De acordo com Gomes (2012b) o currículo descolonizado é uma proposta desafiadora porque implica repensar o currículo sob o prisma da diversidade cultural e exige do educador recontar as narrativas sobre o negro, sem estigmatizações, dando-lhe voz e visibilidade (Silvério, Trinidad, 2012; Coelho et al, 2016). Sendo assim, torna-se 
necessário descontruir ideias racistas que foram instituídas no imaginário social e que são reproduzidas cotidianamente na escola (Santos et al, 2013).

A concepção de currículo descolonizado exige narrarmos a história do africano e do negro brasileiro por meio de sua própria percepção e cultura, rompendo com a visão eurocêntrica de currículo. Isso implica o desenvolvimento de ações e práticas pedagógicas que valorizem as diferenças e permitam a valorização das vozes dos sujeitos negros (Santos, 2009; Santos et al, 2013, 2014, 2016).

Desse modo, o currículo descolonizado contribui para o enfrentamento do racismo e para a efetivação de direitos da população negra (Gomes, 2012b). O currículo multicultural, por sua vez, valoriza a diversidade cultural, superando visões estereotipadas em relação aos africanos e afro-brasileiros (Canen, Moreira, 2007, 2008).

Portanto, refletir sobre essas propostas curriculares tornou-se indispensável na realização de uma educação para as relações étnico-raciais e implementação da Lei n. ${ }^{\circ}$ 10.639/2003 na Educação Básica e Ensino Superior. Tal pretensão é apontada pelos Planos de Educação que regem a educação da Amazônia Bragantina, sendo um avanço no desenvolvimento de um trabalho pedagógico que valorize as diferenças culturais.

A seguir apresentamos uma síntese acerca dos principais discursos dos Planos de Educação analisados acerca das Relações Étnico-Raciais e Lei n. ${ }^{\circ}$ 10.639/2003, considerando elementos da teoria de Bakhtin sobre a linguagem, a saber: gênero do discurso (documento), agente enunciador (aquele que fala) e enunciação discursiva (síntese).

\section{Quadro 1. Síntese dos discursos dos Planos de Educação da Amazônia Bragantina sobre a temática étnico-racial.}

\begin{tabular}{|c|c|c|c|}
\hline Gênero do & Ano & Agente enunciador & Enunciações discursivas \\
\hline $\begin{array}{l}\text { Plano Estadual de } \\
\text { Educação do Pará }\end{array}$ & 2015 & $\begin{array}{l}\text { Conselho Estadual } \\
\text { de Educação do } \\
\text { Pará }\end{array}$ & 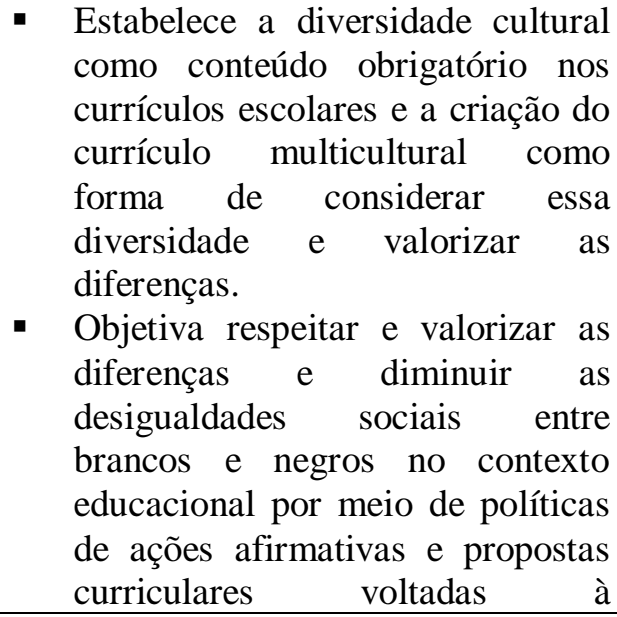 \\
\hline
\end{tabular}




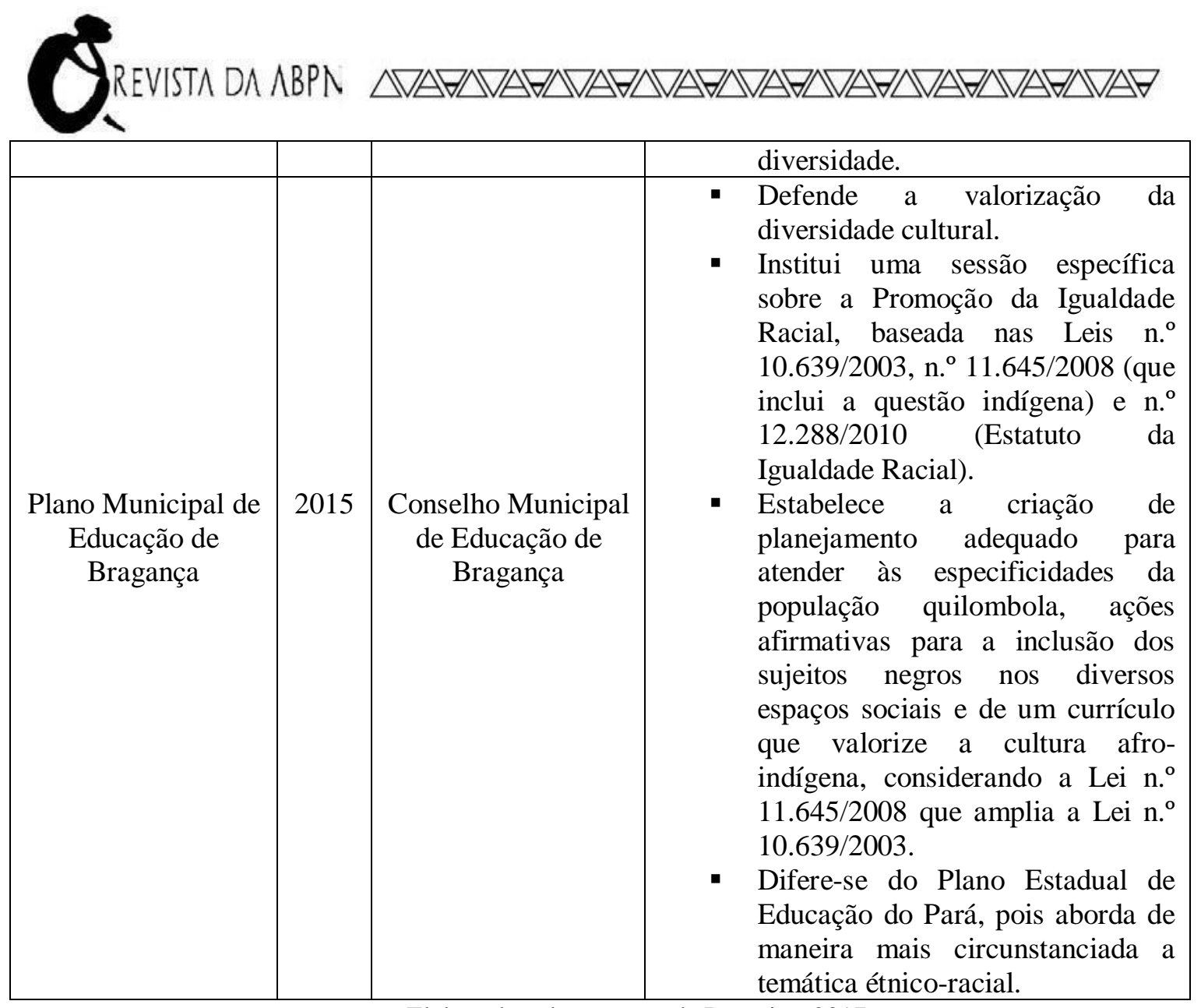

Fonte: Elaborada pelos autores da Pesquisa, 2017.

\section{RELAÇÕES ÉTNICO-RACIAIS E O ENSINO DE HISTÓRIA E CULTURA AFRICANA E AFRO-BRASILEIRA: SOB OS DISCURSOS DAS RESOLUÇÕES DO CONSELHO ESTADUAL DE EDUCAÇÃO DO PARÁ E CONSELHO MUNICIPAL DE EDUCAÇÃO DE BRAGANÇA}

A legislação antirracista brasileira é fundamentalmente importante para o enfrentamento ao racismo, preconceito e discriminação raciais no contexto educacional. Diante disso, quais as contribuições de órgãos como os Conselhos de Educação para a efetividade dessa legislação, especialmente da Lei n. ${ }^{\circ}$ 10.639/2003 no currículo oficial? $\mathrm{O}$ que eles têm a dizer sobre as questões étnico-raciais? Essas e outras indagações direcionaram nossas análises acerca de algumas Resoluções do Conselho Estadual de Educação do Pará e Conselho Municipal de Educação de Bragança/PA.

As Resoluções em sua maioria acostam-se em questões administrativas, portanto, não versam diretamente sobre a temática étnico-racial. Desse modo, abordam acerca da normatização dos processos de autorização, fiscalização e avaliação, intervenções na estrutura física das escolas, etc. Entretanto, na garimpagem dessas Resoluções encontramos duas que, especificamente, frisam a temática, são elas: 
Resolução n. ${ }^{\circ}$ 01/2010 do Conselho Estadual de Educação do Pará e Resolução n. ${ }^{\circ}$ 01/2017 do Conselho Municipal de Educação de Bragança.

A Resolução n. ${ }^{\circ}$ 01, de 05 de Janeiro de 2010, do Conselho Estadual "dispõe sobre a regulamentação e a consolidação das normas estaduais e nacionais aplicáveis à Educação Básica no Sistema Estadual de Ensino do Pará” (Pará, 2010, p. 01), elaborada sob a coordenação de Roberto Ferraz Barreto; a Resolução n. ${ }^{\circ}$ 01, de 07 de janeiro de 2017, do Conselho Municipal, por sua vez, elaborada sob a coordenação de Maria de Nazaré Reis Alexandre, “dispõe sobre a regulamentação e a consolidação das normas municipais, estaduais e nacionais aplicáveis à Educação Básica no Sistema Municipal de Ensino de Bragança/Pará” (Bragança, 2017, p. 01).

O Conselho Estadual de Educação do Pará tem a função de intervir nas escolas da Educação Básica da rede pública estadual e privada, especialmente quando há necessidade de realização de mudanças estruturais (Pará, 2010). Sua finalidade é:

[...] normatizar e supervisionar o Sistema Estadual de Educação, assegurando sua sustentabilidade e a oferta de educação de qualidade para a formação étnicosocial do cidadão, com participação democrática garantindo a inclusão e o respeito à diversidade, visando o desenvolvimento sustentável do estado [...] (Pará, 2010, p. 9).

O Conselho Estadual tem seu primeiro regimento aprovado no ano de 1998 (Pará, 2010), sob a égide da LDB n. ${ }^{\circ}$ 9.394/1996, influenciado pelos movimentos reformistas de educação que desejavam construir uma educação democrática em todo o país (Oliveira, 1997). Por isso, discorre também sobre a formação cidadã, incluindo a dimensão étnica a esse processo, sinalizando imediatamente a contribuição dos movimentos sociais negros para a proposta curricular brasileira (Rocha, 2014; Santos et al, 2013).

O Conselho Municipal de Educação de Bragança é instituído em 2010 por meio da Lei n. ${ }^{\circ}$ 4.042, mas somente em 2016, instala-se o Conselho Municipal de Educação em Bragança, tendo o seu Regimento Interno aprovado no mesmo ano pelo Conselho Pleno e aprovadas as alterações em fevereiro de 2017, iniciando efetivamente suas atividades nesse período. Esse Conselho objetiva a normatização do sistema municipal de ensino e evoca as pretensões para a educação da Amazônia Bragantina, estabelecendo diretrizes gerais para a realização de um trabalho educativo de cunho democrático.

Inicialmente destacamos que o Conselho Estadual de Educação do Pará deve assegurar a "[...] inclusão e o respeito à diversidade [...]" (Pará, 2010), estabelecendo 
uma educação que reconheça as diferenças e valorize a diversidade cultural (Gomes, 2003; André, 2008). Com efeito, Gomes (2012a), Santos (2009) e Munanga (2004) asseveram que respeitar a diversidade cultural implica enfrentar o racismo, preconceito e discriminação racial e garantir um espaço de liberdade para a expressão dessa diversidade.

Diante disso, as Resoluções estabelecem como um dos princípios da educação escolar o "[...] compromisso com uma educação antirracista pela vivência de relações étnico-raciais e a promoção do bem de todos sem preconceito e sem outras formas de discriminação [...]” (Pará, 2010, p. 02; Bragança, 2017, p. 02), ampliando o que estava previsto na LDB n. ${ }^{\circ}$ 9.394/1996 que elencou como princípio da educação nacional apenas a “[...] consideração com a diversidade étnico-racial [...]” (Brasil, 1996, p. 02).

Esse discurso revela a importância da escola possibilitar experiências étnicoraciais aos alunos, ou seja, atividades que envolvam todos em um movimento de integração da diversidade cultural (Santos et al, 2013). As autoras apontam ser necessário a escola favorecer o respeito à diversidade cultural por meio do ensino a fim de construir essas vivências. Nesse sentido, o contato com a história dos africanos e afro-brasileiros pode esclarecer a visão que os outros estudantes têm a seu respeito, desconstruindo estereótipos e preconceitos relacionados à raça (Santos et al, 2013).

Na mesma direção, Gomes (2003) assevera que as experiências na escola podem contribuir na realização de experiências étnico-raciais, porém, também pode desencadear representações negativas em relação à identidade do negro. Ou seja, a escola pode propiciar relações sociais capazes de estimular o respeito às diferenças, como também pode engendrar processos de discriminação racial (Santos, 2009).

Por isso, o educador deve estar consciente dos conteúdos ideológicos que permeiam a proposta curricular, a fim de descristalizar àqueles de caráter eurocêntrico e excludente, além de estar atento às relações interpessoais entre os alunos para que interfira adequadamente, pois "[...] experiências de preconceito racial vividas na escola [...] ficam guardadas na memória [...]" (Gomes, 2003, p. 176), causando danos geralmente irreparáveis para os que sofrem o racismo, preconceito e discriminação raciais (Munanga, 2004).

Diante disso, a escola precisa desenvolver um trabalho pedagógico diferenciado para que o ensino eurocêntrico seja desconstruído e ceda lugar à uma educação para as relações étnico-raciais (Santos et al, 2013). Oficinas, palestras, seminários, brincadeiras 
são exemplos de atividades que podem contribuir para a efetividade de uma educação antirracista e que permita o reconhecimento dos sujeitos negros, garantindo sua integração ao contexto social, especificamente, o espaço escolar (Coelho et al, 2016).

Nesse sentido, através de um ensino não eurocêntrico é possível desenvolver experiências de aprendizagem em relação à cultura de outros povos, o exercício da cidadania, o respeito à diversidade cultural, a tolerância, a valorização do outro, a desconstrução de preconceitos e de ideias racistas, etc. (Munanga, 2004). Contudo, para que isso se efetive é necessário que a escola propicie "[...] o conhecimento de nossa diversidade cultural e pluralidade étnica, bem como a necessária informação sobre os bens culturais de nosso rico e multifacetado patrimônio histórico [...]" (Fernandes, 2005, p. 386).

A educação, se baseada no ensino não eurocêntrico, poderá contribuir para a superação das desigualdades sociais, disparidades entre brancos e negros no contexto educacional, enfrentamento ao racismo e garantia da cidadania da população negra. A formação cidadã advinda desse tipo de ensino contribui indiscutivelmente para que os alunos aprendam a respeitar e a reconhecer a cidadania do outro (Santos et al, 2013, 2016), sinalizando para a realização de uma educação multicultural, pautada na formação cidadã, democrática e para a diversidade cultural (Gadotti, 1992).

Segundo Gadotti (1992, p. 21), a concepção de educação multicultural para a formação humana exige da escola abrir "[...] os horizontes de seus alunos para a compreensão de outras culturas, de outras linguagens e modos de pensar, num mundo cada vez mais próximo, procurando construir uma sociedade pluralista e interdependente [...]". Essa educação assemelha-se a proposta de currículo multicultural defendida pelo Plano Estadual de Educação do Estado do Pará, configurando-se como um tipo de educação que contempla as demandas dos diferentes grupos étnico-raciais no currículo oficial.

Nessa perspectiva, é oportuno frisar que as Resoluções analisadas tornam explícita sua preocupação com a garantia do respeito à diversidade, incluindo a dimensão multicultural no cerne da proposta curricular para a Educação Básica da Amazônia Bragantina. Segundo os documentos, a escola pode evidenciar, através de seu trabalho educativo, que é possível conviver com as diferenças e respeitar a diversidade (Pará, 2010; Bragança, 2017), de forma respeitosa e valorativa, visibilizando, portanto, os diferentes sujeitos para além de uma visão eurocêntrica de ensino. 
Mais especificamente, no tocante a implementação da Lei n. ${ }^{\circ}$ 10.639/2003 no currículo oficial, as Resoluções determinam que “[...] o ensino da História do Brasil levará em conta a diversidade étnico-racial que contribuiu para a formação do povo brasileiro, especialmente as matrizes indígenas, africanas e europeias [...]" (Pará, 2010, p. 5; Bragança, 2017, p. 7), destacando a colaboração da população negra para a constituição da nação, em vários aspectos, como econômico, social, cultural (Silvério, Trinidad, 2012), implicando na valorização desse grupo étnico-racial.

Nesse sentido, a Lei n. ${ }^{\circ}$ 10.639/2003 contribui para a valorização da população negra, pois evidencia sua contribuição para a formação do país, superando representações negativas presentes no imaginário social brasileiro (Munanga, 2004). Contudo, o problema para que essa superação ocorra se refere ao racismo "[...] que hierarquiza, desumaniza e justifica a discriminação existente [...]” (Munanga, 2004, p. 53), realidade evidente nas instituições de ensino que, historicamente, invisibilizaram o sujeito negro (Coelho, 2006).

O racismo é um fenômeno muito complexo que não se restringe a manifestações concretas de preconceito e discriminação, pois permeia a mente implicitamente (Carone; Bento, 2014), emergindo de maneira muito sutil nas relações sociais. Munanga (2004) assevera que esse fenômeno tem causado interferências negativas no contexto escolar para a realização de uma educação para a diversidade cultural, engendrando, inevitavelmente, processos de exclusão social. Por isso, deve ser uma questão presente nas discussões acadêmicas e na política do Estado (Santos, 2014b).

Cavalleiro (2001), por sua vez, abaliza que o racismo na sociedade brasileira é de caráter estrutural, internalizado nas relações sociais e institucionalizado em diferentes segmentos, como se verifica na instituição escolar, sendo reproduzido tácita e inconscientemente através das práticas pedagógicas, devendo ser enfrentado de forma perspicaz com o auxílio de outros agentes, como o Ministério Público, Conselhos de Educação, Movimentos Sociais e Movimentos Negros (Santos, 2014b).

Desse modo, a escola precisa enfrenta-lo por meio de ações e práticas pedagógicas que atendam as questões étnico-raciais (Santos, 2009), principalmente assegurando o Ensino de História e Cultura Africana e Afro-Brasileira, conforme estabelece a Lei n. ${ }^{o}$ 10.639/2003 (Santos et al, 2013). A escola não pode escusar-se de efetivar a Lei, caso contrário, irá reproduzir relações de poder que inferiorizam o negro 
(Schwarcz, 1993) e que reproduzem um racismo à brasileira, sutilmente estruturado, velado e implícito (Telles, 2003).

Em síntese, verifica-se a influência da Lei n. ${ }^{\circ}$ 10.639/2003 na proposta curricular da Educação Básica da Amazônia Bragantina. Porém, são necessárias novas incursões sobre a temática étnico-racial para que os educadores encontrem subsídios para a realização de ações e práticas pedagógicas voltadas à diversidade cultural e valorização das diferenças. Destarte, a partir de uma política intersetorial que integre diferentes agentes sociais, a escola poderá contribuir significativamente para reverter o quadro de desigualdades sociais.

\section{CONSIDERAÇÕES FINAIS}

Esse estudo analisou a implementação da Lei n. ${ }^{\circ}$ 10.639/2003 no currículo oficial de escolas situadas no entorno de manguezais da Reserva Extrativista Marinha Caeté-Taperaçu (Resex-Mar), em Bragança, Pará, a partir dos discursos de documentos oficiais da legislação educacional da Amazônia Bragantina que versam sobre a temática étnico-racial.

As relações étnico-raciais e a Lei n. ${ }^{\circ}$ 10.639/2003 integram uma discussão teórica e política que objetiva descristalizar representações negativas em relação ao africano e negro brasileiro, estigmas que se tornaram hegemônicos no imaginário social da Educação Básica do e Ensino Superior, de caráter eminentemente racista (Munanga, 2004).

Abordar essa temática na escola é, antes de tudo, desenvolver uma nova postura frente à pluralidade, que reconheça e valorize a diversidade cultural (Candau; Moreira, 2007). Para isso, é extremamente importante que os educadores tenham experimentado uma formação acadêmica e social que possibilite a construção dessa nova postura (Coelho et al, 2016).

Os documentos analisados defendem o respeito à diversidade cultural como forma de diminuir as desigualdades sociais, o desenvolvimento de políticas de ações afirmativas como instrumentos de integração da população negra e a criação de proposta curricular multicultural que atenda as demandas dos diferentes grupos étnico-raciais.

Os documentos analisados apresentam apenas discussões tácitas acerca das relações étnico-raciais e da implementação da Lei n. ${ }^{\circ}$ 10.639/2003, contudo, são 
discursos que evidenciam perfeitamente a influência da Lei na política curricular brasileira e nas práticas educativas da Educação Básica e Ensino Superior.

Especificamente, o Plano Estadual de Educação do Pará defende a criação de políticas de ações afirmativas direcionadas aos afro-brasileiros e de um currículo multicultural que contribua para a valorização de sua história e cultura. Por sua vez, o Plano Municipal de Educação de Bragança abaliza a importância de ações afirmativas voltadas à população negra e prevê a elaboração de um currículo que considere as questões étnico-raciais.

Por fim, a Resolução n. ${ }^{\circ}$ 01/2010 do Conselho Estadual de Educação do Pará e a Resolução n. ${ }^{\circ}$ 01/2017 do Conselho Municipal de Educação de Bragança/PA estabelecem que o currículo da Educação Básica deva contemplar as demandas dos diferentes grupos étnico-raciais, especialmente os aspectos relacionados ao Ensino de História e Cultura Africana e Afro-Brasileira, enfatizando a perspectiva da diversidade cultural na proposta curricular.

Desse modo, percebemos a necessidade da implementação da Lei n. ${ }^{\text {o }}$ 10.639/2003 no currículo da Educação Básica e do Ensino Superior, ampliação da discussão sobre a temática étnico-racial e sua inserção na pauta do Estado, a fim de garantir a integração da população negra. Portanto, a efetivação da Lei é uma possibilidade para o Brasil reverter o quadro histórico de desigualdades e garantir a cidadania e a valorização da diversidade cultural.

\section{REFERÊNCIAS}

ANDRÉ, Maria da Consolação. O ser negro: um estudo sobre a construção de subjetividades em afro-brasileiros. Brasília: LGE Editora, 2008.

BAKHTIN, Mikhail. Marxismo e filosofia da linguagem: problemas fundamentais do método sociológico da linguagem. 14. ed. São Paulo: Hucitec, 2010.

BRAGANÇA. Conselho Municipal de Educação. Resolução n. ${ }^{\circ}$ 01, de 01 de Janeiro de 2017. Aprova a regulamentação e a consolidação das normas municipais, estaduais e nacionais aplicáveis à Educação Básica no Sistema Municipal de Ensino de Bragança/PA. Disponível em: www.braganca.pa.gov.br/cmeb. Acessado em: 02 de setembro de 2017.

BRAGANÇA. Lei $n .^{\circ} 4.391$, de 22 de junho de 2015. Institui o Plano Municipal de Educação. Disponível em: http://www.braganca.pa.gov.br/cmeb/index.php/publicacoes. Acessado em: 06 de setembro de 2017.

BRANDÃO, Carlos Rodrigues. O que é educação. São Paulo: Brasiliense, 1981. 
BRASIL. Lei n. ${ }^{\circ}$ 10.639, de 20 de dezembro de 2003. Altera a Lei n. ${ }^{\circ}$ 9.394/1996, que estabelece as Diretrizes e Bases da Educação Nacional, para incluir no currículo oficial das redes de ensino a obrigatoriedade do Ensino de História e Cultura Africana e Afro-Brasileira. Diário Oficial da União, Brasília, DF, 2003. Disponível em: http://www.planalto.gov.br/ccivil_03/leis/2003/110.639.htm. Acessado em: 04 de setembro de 2017.

BRASIL. Lei n. ${ }^{\circ}$ 9.394, de 20 de dezembro de 1996. Estabelece as Diretrizes e Bases da Educação Nacional. Diário Oficial da União, Brasília, DF, 1996. Disponível em: http://www.planalto.gov.br/ccivil_03/leis/19394.htm. Acessado em: 04 de setembro de 2017.

BRASIL. Ministério da Educação. Diretrizes Curriculares Nacionais para a Educação das Relações Étnico-Raciais e para o Ensino de História e Cultura Africana e Afro-Brasileira. Brasília: Secretaria Especial de Políticas de Promoção da Igualdade Racial, 2004.

CANDAU, Vera Maria. Multiculturalismo e Educação: desafios para a prática pedagógica. In: CANDAU, Vera Maria; MOREIRA, Antônio Flávio Barbosa. Indagações sobre currículo: currículo, conhecimento e cultura. Brasília: Ministério da Educação, Secretaria de Educação Básica, 2007.

CANDAU, Vera Maria; MOREIRA, Antônio Flávio Barbosa (org.). Multiculturalismo: diferenças culturais e práticas pedagógicas. Petrópolis: Vozes, 2008.

CARONE, Iray; BENTO, Maria Aparecida Silva. Psicologia social do racismo: estudos sobre branquitude e branqueamento no Brasil. 6. ed. Petrópolis: Vozes, 2014.

CAVALLEIRO, Eliane dos Santos (org.). Racismo e anti-racismo na educação: repensando nossa escola. 3. ed. São Paulo: Selo Negro, 2001.

CHIZZOTTI, Antonio. Pesquisa qualitativa em ciências humanas e sociais. 3. ed. Petrópolis: Vozes, 2010.

COELHO, Wilma de Nazaré Baía et al (org.). A diversidade em discussão: inclusão, ações afirmativas, formação e práticas docentes. São Paulo: Livraria da Física, 2016.

COELHO, Wilma de Nazaré Baía. A cor ausente: um estudo sobre a presença do negro na formação de professores - Pará, 1970-1989. Belo Horizonte: Mazza Edições, 2006.

COELHO, Wilma de Nazaré Baía; COELHO, Mauro Cezar. Raça, cor e diferença. (org.). Belo Horizonte: Mazza Edições, 2008.

FERNANDES, José Ricardo Oriá. Ensino de história e diversidade cultural: desafios e possibilidades. Caderno Cedes, v. 25, n. 67, 2005, p. 378-388.

FREIRE, Paulo. Educação como prática da liberdade. 24. ed. São Paulo: Paz e Terra, 2000.

FREIRE, Paulo. Pedagogia da autonomia: saberes necessários à prática educativa. 36. ed. São Paulo: Paz e Terra, 2009.

GOMES, Nilma Lino (org.). Práticas pedagógicas de trabalho com relações étnico-raciais na escola na perspectiva da Lei n. ${ }^{\circ}$ 10.639/2003. Brasília: Ministério da Educação; Unesco, 2012b. 
GOMES, Nilma Lino. Diversidade e currículo: indagações sobre o currículo do ensino fundamental. Brasília: Ministério da Educação, Secretaria de Educação à Distância, 2007.

GOMES, Nilma Lino. Educação, identidade negra e formação de professores/as: um olhar sobre o corpo negro e o cabelo crespo. Educação e Pesquisa, v. 29, n. 1, 2003, p. 167-182.

GOMES, Nilma Lino. Relações étnico-raciais, educação e descolonização dos currículos. Currículo sem fronteiras, v. 12, n. 1, 2012a, p. 98-109.

HALL, Stuart. A identidade cultural na pós-modernidade. Rio de Janeiro: DP\&A Editora, 2001.

HASENBALG, Carlos Alfredo. Discriminação e desigualdades raciais no Brasil. 2. ed. Belo Horizonte: Editora UFMG, 2005.

LIMA, Telma Cristiane Sasso de; MIOTO, Regina Célia Tamaso. Procedimentos metodológicos na construção do conhecimento científico: a pesquisa bibliográfica. Revista Katálysis, v. 10, [edição especial], 2007, p. 37-45.

MOREIRA, Antônio Flávio Barbosa; CANDAU, Vera Maria. Educação escolar e cultura(s): construindo caminhos. Revista Brasileira de Educação, [s/v], n. 23, 2003, p. 156-168.

MUNANGA, Kabengele. Algumas considerações sobre "raça", ação afirmativa e identidade negra no Brasil: fundamentos antropológicos. Revista USP, [s/v], n. 68, 2005-2006, p. 46-57.

MUNANGA, Kabengele. O negro na sociedade brasileira: resistência, participação e contribuição. Brasília: Fundação Cultural Palmares-MinC, 2004.

OLIVEIRA, Regina Tereza Cestari de. A LDB e o contexto nacional: o papel dos partidos políticos na elaboração dos projetos, 1988 a 1996. Tese (Doutorado em Educação). Universidade Estadual de Campinas, SP, 1997.

ORTIZ, Renato. Cultura brasileira e identidade nacional. São Paulo: Brasiliense, 2006.

PARÁ. Conselho Estadual de Educação. Resolução n. ${ }^{\circ} 01$, de 05 de Janeiro de 2010. Aprova a regulamentação e a consolidação das normas estaduais e nacionais aplicáveis à Educação Básica no Sistema Estadual de Ensino do Pará. Disponível em: www.cee.pa.gov.br. Acessado em: 02 de setembro de 2017.

PARÁ. Lei n. ${ }^{\circ}$ 8.186, de 23 de Junho de 2015. Aprova o Plano Estadual de Educação. Disponível em: http://www.cee.pa.gov.br/sites/default/files/PLANO\%20ESTADUAL\%20DE\%20EDUCA\%C3 \%87\%C3\%83006052015_0.pdf. Acessado em: 06 de setembro de 2017.

ROCHA, José Geraldo da. Movimentos sociais e negritude no Brasil. Revista da Associação Brasileira de Pesquisadores/as Negros/as (ABPN), v. 6, n. 12, 2013-2014, p. 24-60.

SANTOS, Raquel Amorim dos et al (org.). Lei n. $^{\circ}$ 10.639/2003: pesquisas e debates. São Paulo: Livraria da Física, 2014a.

SANTOS, Raquel Amorim dos. (In) visibilidade negra: representação social de professores acerca das relações raciais no currículo escolar do Ensino Fundamental em Ananindeua (PA). Dissertação (Mestrado em Educação). Universidade Federal do Pará, Belém-PA, 2009. 
SANTOS, Raquel Amorim dos. Ciclo de política curricular do estado do Pará (2008-2012): a enunciação discursiva sobre relações "raciais". Tese (Doutorado em Educação). Universidade Federal do Pará, Belém-PA, 2014b.

SANTOS, Raquel Amorim dos; COELHO, Wilma de Nazaré Baía. Política Curricular e Relações Raciais: O Estado da Arte nas Produções da ANPED. Revista da Associação Brasileira de Pesquisadores/as Negros/as (ABPN), v. 8, n. 20, 2016, p. 111-134.

SANTOS, Raquel Amorim dos; COELHO, Wilma de Nazaré Baía; SILVA, Rosângela Maria de Nazaré Barbosa e (org.). Ensino em Pesquisa: investigações sobre a educação das relações étnico-raciais. Belém: Editora Açaí, 2013.

SANTOS, Raquel Amorim dos; COELHO, Wilma de Nazaré Baía; SILVA, Rosângela Maria de Nazaré Barbosa e. Educação e Diversidade na Amazônia. São Paulo: Livraria da Física, 2015.

SANTOS, Raquel Amorim dos; SILVA, Rosângela Maria de Nazaré Barbosa e. Racismo científico no Brasil pós-escravatura. Revista Contemporânea de Educação, v. 12, n. 25, 2017, p. 438-454.

SÁ-SILVA, Jackson Ronie; ALMEIDA, Cristóvão Domingos de; GUINDANI, Joel Felipe. Pesquisa documental: pistas teóricas e metodológicas. Revista Brasileira de História \& Ciências Sociais, v. 1, n. 1, 2009, p. 1-15.

SCHWARCZ, Lilia Mortiz. O espetáculo das raças: cientistas, instituições e questão racial no Brasil, 1870-1930. São Paulo: Companhia das Letras, 1993.

SILVA, Tomaz Tadeu da. Documentos de identidade: uma introdução às teorias do currículo. 3. ed. Belo Horizonte: Autêntica, 2009.

SILVÉRIO, Valter Roberto; TRINIDAD, Cristina Teodoro. Há algo novo a se dizer sobre as relações raciais no Brasil contemporâneo? Educação \& Sociedade, v. 33, n. 120, 2012, p. 891914. 